\title{
Formation of tropical storms in an atmospheric general circulation model
}

\author{
By SUZANA J. CAMARGO ${ }^{1 *}$ and ADAM H. SOBEL ${ }^{2},{ }^{1}$ International Research Institute for Climate \\ Prediction, The Earth Institute of Columbia University, Lamont Campus, PO Box 1000, Palisades, NY \\ 10964-8000,USA; ${ }^{2}$ Department of Applied Physics and Applied Mathematics and Department of Earth and \\ Environmental Sciences, Columbia University, New York, NY 10027, USA
}

(Manuscript received 20 January 2003; in final form 26 May 2003)

\begin{abstract}
The formation of tropical storms in a low-resolution Atmospheric General Circulation model is studied over the western North Pacific region during the June-October season. The model simulates the mean annual cycle of storm number in this basin quite well. Time-dependent composites of the storms are formed and analyzed, with a focus on the temporal evolution of quantities averaged in space around the storm centers. Day zero of each composite corresponds to the time at which the disturbance passes criteria for detection. The composites depict the model storms as convectively coupled, synoptic-scale vortices whose degree of coupling to convection increases at some point, leading to intensification. Variables related to disturbance intensity have significant anomalies at day -7 , indicating a finite amplitude disturbance prior to "genesis". Many of these variables show similar temporal evolution, with a local minimum two or three days before day zero, and a strong increase after that for several days, followed by an eventual decrease. The precipitation reaches its maximum on day 2 , the net moist static energy forcing (surface fluxes minus net tropospheric radiative cooling, each of which has an anomaly of $20-30 \mathrm{~W} \mathrm{~m}^{-2}$ in the sense of warming the atmosphere) a day later, and dynamical variables such as vorticity and temperature still later, with broad plateaus centered around day 4 or 5 . The vorticity increases at the surface at the same time as at midlevels, unlike in observed storms. The mean composite environmental vertical wind shear has a maximum amplitude on day -2 and then decreases. This could indicate a causal role of shear in limiting development, but would also be consistent with a coincidental storm motion to regions of lower shear, with development controlled by other factors. A signal in the skewness of the lower-level relative humidity distribution over the ensemble suggests that a dry lower troposphere can prevent development of a model tropical disturbance.
\end{abstract}

\section{Introduction}

Model tropical storms having gross features similar to observed tropical cyclones have long been studied in low-resolution Atmospheric General Circulation Models (GCMs) (Manabe et al., 1970). The intensity is much lower and spatial scale much larger in the simulated storms than in observed tropical cyclones (Bengtsson et al., 1982; Vitart et al., 1997). The climatology, structure, and interannual variability of these model tropical storms has been analysed (Bengtsson et al., 1982, 1995; Wu and Lau, 1992). More recently, Vitart et al. (1997) studied model tropical storms in GCMs using an ensemble of integrations and explored their relation to the large-scale circulation (Vitart et al., 1999) and sea surface temperature variability (Vitart and Anderson, 2001). Studies of model tropical cyclones using global high resolution models have also been performed, but for more

*Corresponding author.

e-mail: suzana@iri.columbia.edu limited time periods (Krishnamurti and Oosterhof, 1989; Chan and Kwok, 1999).

While low-resolution GCMs are clearly not adequate for forecasts of individual storms, this does not rule out their having some skill for dynamical seasonal forecasts of tropical cyclone activity (Bengtsson, 2001). Although statistical methods applied to observations appear to be in wider use for this purpose (e.g. Gray et al., 1993; Nicholls, 1992; Chan et al., 1998), dynamical forecasts of seasonal tropical storm activity are currently produced at ECMWF (European Centre for Medium-Range Weather Forecasts) using coupled ocean-atmosphere GCMs (Vitart and Stockdale, 2001).

There are basically two methods of using a GCM to forecast tropical cyclone activity. One method uses the GCM to predict large-scale variables which affect tropical cyclone activity (Ryan et al., 1992; Watterson et al., 1995; Thorncroft and Pytharoulis, 2001). The other method involves detecting and tracking the tropical storms in the model itself, and then basing the prediction on the statistics of those storms (Manabe et al., 1970; 
Bengtsson et al., 1982; Krishnamurti, 1988; Krishnamurti et al., 1989; Broccoli and Manabe, 1990; Wu and Lau, 1992; Haarsma et al., 1993; Bengtsson et al., 1995; Tsutsui and Kasahara, 1996; Vitart et al., 1997; Vitart and Stockdale, 2001). Despite the low intensities and large spatial scales of the model storms, their spatial and temporal distributions are often similar to those of observed storms (Bengtsson et al., 1995; Vitart et al., 1997), suggesting that this approach has some chance of success. To the extent that this method of seasonal forecasting assumes some confidence in the model's ability to produce storms in (statistically) the right places and times for the right reasons, it is desirable to obtain a clearer picture of the tropical storms' formation process in the GCM. The present study aims to document this process in a time-dependent way, at least in one particular model, as a step towards understanding it better. Previous studies of tropical storms in GCMs have focused on the instantaneous spatial structure of the storms (Bengtsson et al., 1982; 1995; Vitart et al., 1997). Here, we take a different approach, focusing primarily on spatial averages over the entire (composite) storm, but looking at the temporal structure of those averages in order to understand the storms' genesis and evolution.

Besides practical considerations associated with forecasting, it is also of some basic interest to us to understand how GCMs can have reasonable tropical storm climatologies at resolutions far from those necessary to simulate tropical cyclone dynamics realistically. Tropical cyclones are highly nonlinear phenomena. We might reasonably expect that getting their amplitudes and spatial scales right would be a prerequisite to getting the statistics of their occurrence right, but this seems not necessarily to be the case. Something other than the small-scale details of true tropical cyclone dynamics must be playing a role in determining (statistically) when and where they occur. Understanding this might have some relevance, indirectly, to an understanding of what determines the storms' statistics in reality. We do not directly address this question here, but it helps motivate us to study the development of tropical storms in a low-resolution model. Such a model presumably feels the same large-scale constraints as the real atmosphere, but cannot respond by forming realistic tropical cyclones. It instead forms whatever analogous disturbances it can to satisfy those constraints, whatever they may be; understanding these disturbances better may help us to understand what the constraints are and how they operate.

Western North Pacific model tropical storms are studied here in simulations with low-resolution (T42) GCM, specifically ECHAM4.5 (Roeckner et al., 1996). This model at this resolution is used at the International Reasearch Institute for Climate Prediction (IRI) for routine seasonal forecasts (Mason et al., 1999; Goddard et al., 2001). The possibility of using this model at this resolution for operational forecasting of tropical cyclone activity is being presently considered. Higher resolution would have obvious advantages, and is also being considered using regional climate models in various domains (e.g. Landman et al., 2002). However, tropical cyclones are only one variable of many that must be forecast, and the others are not nearly as sensitive to resolution. There is a distinct advantage in cost and efficiency to using the same models, resolution and number of ensemble members for tropical cyclone forecasts as are used in the current IRI operational seasonal forecasts (Mason et al., 1999; Goddard et al., 2001). In this study, similarly, our reason for using a lowresolution ensemble versus a single run of a higher resolution model is largely practical. The simulations, produced for other purposes, were available to us. An advantage is that the ensemble of long model integrations gives us a large statistical sample and robust features in the composites. Previous studies using an earlier version of the same GCM, but with a higher resolution (T106) (Bengtsson et al., 1995) showed, unsurprisingly, that the model tropical storms' characteristics can be improved by using a finer resolution. However, resolution is not the only factor influencing the model storms' properties. A previous study comparing different models' tropical storms (Camargo and Zebiak, 2002b) showed that different GCMs can have very different numbers of storms (both climatology and interannual variability) in any given basin, and that the best results are not always obtained with the highest resolution model. Other factors, such as each

Western North Pacific domain

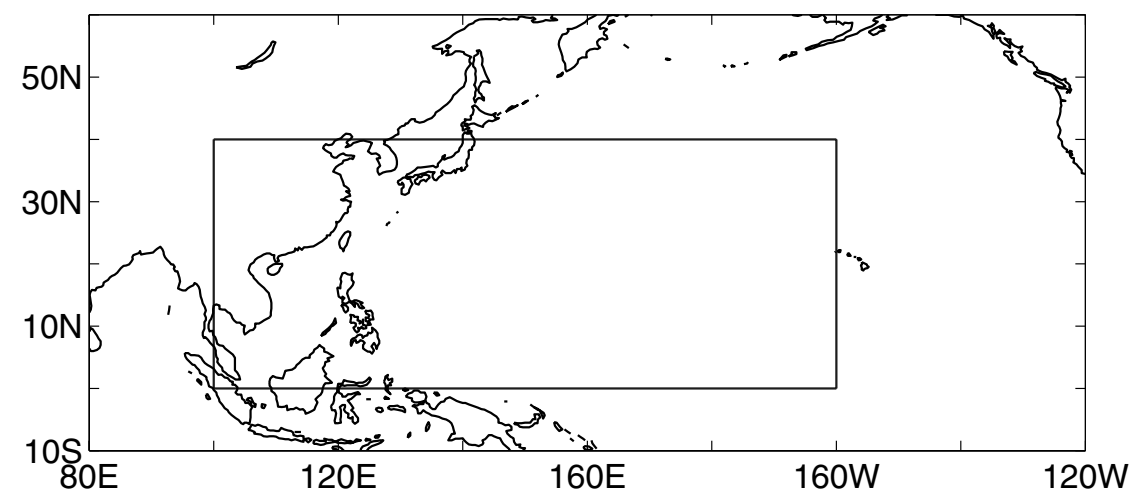

Fig 1. Definition of the western North Pacific basin domain used in this study. 
model's physical parameterizations, apparently play a part as well.

The general features of the model tropical storms in the western North Pacific and the compositing technique are described in section 2. The characteristics of the composites and our main results are given in section 3, and we conclude in section 4 .

\section{Time composites of western North Pacific model tropical storms}

This study uses model data from a 13-member ensemble of ECHAM4.5 (Roeckner et al., 1996) simulations using T42 reso-

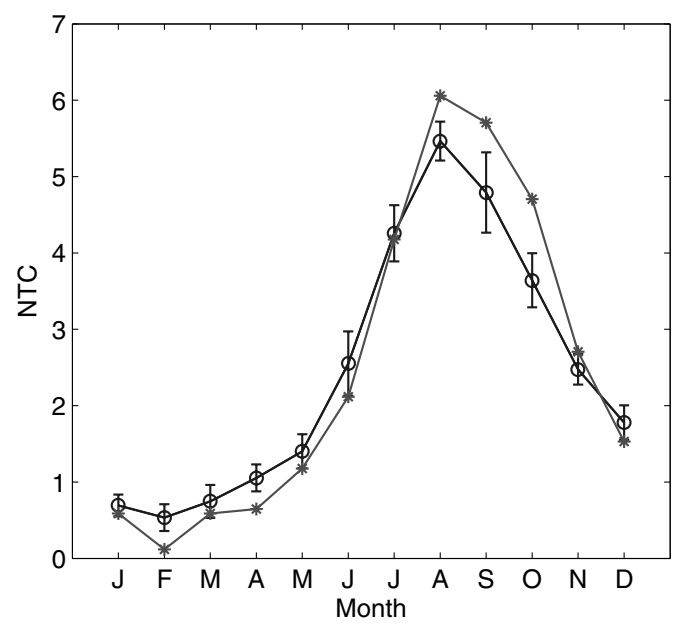

Fig 2. Annual cycle of number of tropical storms in the western North Pacific basin: (o) ensemble mean of ECHAM4.5 (*) JTWC observed named tropical storms.

(a)

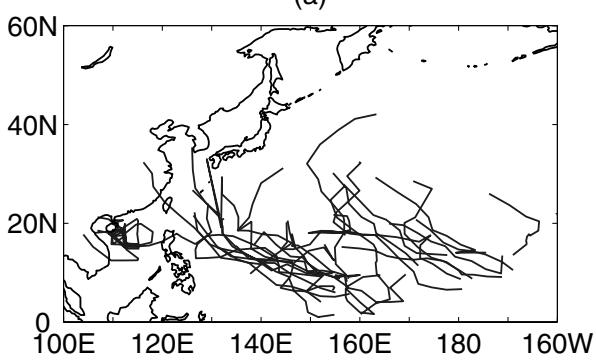

(b)

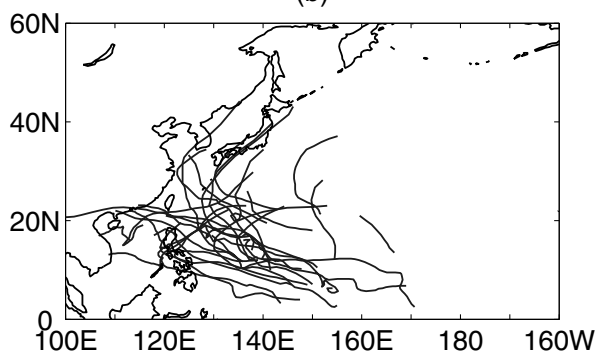

Fig 3. Tracks of (a) one ensemble member model tropical storms (b) JTWC observed named tropical storms in the western North Pacific in 1980. lution and observed monthly mean sea surface temperatures for the period 1979-1995. The observational data used in Figs. 2 and 3 are from the Joint Typhoon Warning Center (JTWC) best track dataset (JTWC, 2002); the named tropical storms occuring in the period 1979-1995 were used for comparison with the model data.

Model tropical storms are detected and tracked globally using a basin and model-dependent algorithm, incorporating multiple physical fields, as described in Camargo and Zebiak, (2002a). The algorithm has two parts, detection and tracking, described below. Time-dependent composites of model tropical storms are then analyzed. Each storm in each ensemble member was treated as an independent case in construction of the composites.

The detection and tracking algorithms are discussed in detail in Camargo and Zebiak (2002a); here only a short summary is given. The detection algorithm is similar to others which can be found in the literature, as reviewed in Vitart (1998). These methods detect a model tropical cyclone when chosen dynamical and thermodynamical variables exceed thresholds determined from observed tropical storm climatology. Most studies (Bengtsson et al., 1982; Vitart et al., 1997) use a single set of threshold criteria globally. However, threshold criteria taken from observational climatological values do not account for model biases and deficiencies. We use basin- and model-dependent threshold criteria, based on the model climatology at each ocean basin. Basin-dependent threshold criteria were obtained for three variables: low-level vorticity ( $850 \mathrm{hPa})$, surface wind speed and vertically integrated local temperature anomaly (using three pressure levels: 700, 500 and $300 \mathrm{hPa}$ ). A model tropical storm must have anomalies in these three fields, each averaged over a region of size $5 \times 5$ model grid boxes, which simultaneously exceed their respective thresholds. A model storm must also have a local minimum of sea level pressure, positive temperature anomalies at several different pressure levels, and local mean wind speed larger at $850 \mathrm{hPa}$ than at $300 \mathrm{hPa}$. The storm must satisfy these criteria for a minimum of two days.

After all the criteria above are satisfied, the model tropical disturbance is tracked using only the low-level vorticity $(850 \mathrm{hPa})$, the centroid of which defines the center of the disturbance. The disturbance is tracked forward and backward in time, centered on the first time that it passes all the criteria described above. The tracking continues until the value of the low-level vorticity is smaller than a relaxed threshold, smaller than that used initially to detect the storm. The reader is referred to Camargo and Zebiak (2002a) for further details.

Only tropical storms that form in the western North Pacific basin region shown in Fig. 1 are considered in this study. A reason for selecting this region is that the annual cycle of tropical disturbance frequency produced by the model in the western North Pacific is very similar to the annual cycle of tropical cyclone frequency which is observed there, as seen in Fig. 2. Observed interannual variability of tropical cyclone activity in the western North Pacific basin is fairly small, and the model has low, but 
(a)

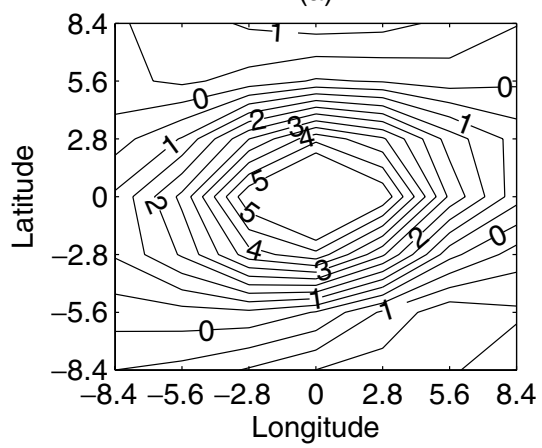

(c)

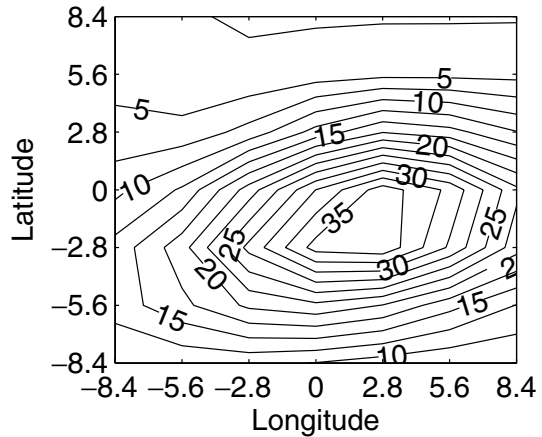

(b)

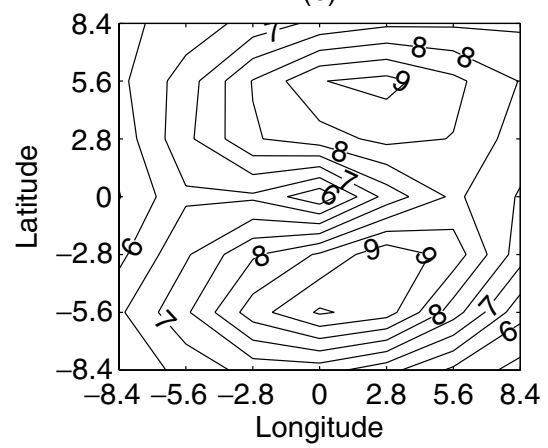

(d)

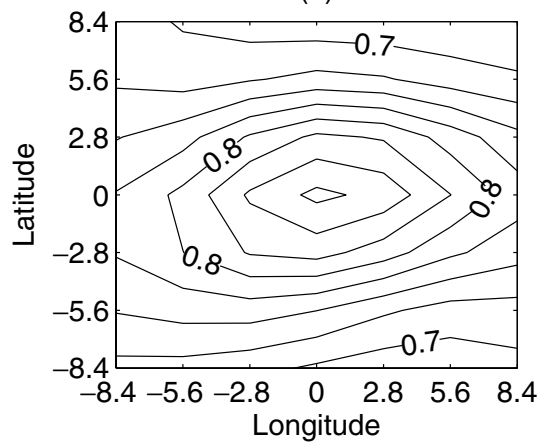

Fig 4. Contour plots of composite variables at day 0: (a) vorticity $850 \mathrm{hPa}\left(\times 10^{-5} \mathrm{~s}^{-1}\right)$, (b) surface windspeed (m s$\left.{ }^{-1}\right)$, (c) precipitation (mm d ${ }^{-1}$ ), (d) relative humidity $850 \mathrm{hPa}$. Latitude and longitude of the composites are measured from the storm center.

significant skill at predicting this variability. According to ENSO phase, the average genesis location of model storms exhibits a northwest-southeast shift (Camargo and Zebiak, 2002b), similar to that observed (Lander, 1994; Chen et al., 1998; Chia and Ropelewski, 2002; Wang and Chang, 2002). Storm tracks in the model and observations in one typical year (1980) are shown in Fig. 3. Compared to observed cyclones, fewer model storms recurve as they move poleward (Camargo and Zebiak, 2002a). The model also has a number of tracks occurring substantially further east than any in the observations. The eastward bias is a general feature of the model, occurring in all years in most of the ensemble members. The erroneous displacement of the easternmost tracks is on the order of $2000 \mathrm{~km}$. While this may seem large, it is not significantly greater than the horizontal extent of a typical model disturbance (Fig. 4), and is therefore modest from a dynamical point of view.

This study concentrates on the western North Pacific, the basin with the highest fraction of the total global number of tropical cyclones. The ECHAM4.5 tropical storms' interannual variability in most basins is also significantly correlated to the observed interannual variability (Camargo and Zebiak, 2002a,b). However, there is a strong bias in the model, in the sense that the model produces a global and annual mean number of model tropical storms much lower than the observed one. The Atlantic has a particularly low annual mean number, climatologically. A region where the model does not reproduce the shape of the annual cycle very well is the North Indian Ocean, where the climatological number of model tropical cyclones per month has a peak in the northern Hemisphere summer, in contrast with the observed cycle, which has a peak in May and another in October, with a minimum during the Indian summer monsoon.

The period covered in the simulations, 1979-1995, has a few ENSO (El Niño Southern Oscillation) events. The number of model storms' interannual variability is affected by these ENSO events in the Atlantic, South Pacific and Australian regions. In the western North Pacific the main effect of ENSO is to shift the location of the model and observed tropical cyclone activity, with the total number of storms unchanged, as is observed (Lander, 1994; Chen et al., 1998; Chia and Ropelewski, 2002; Wang and Chang, 2002).

Time-dependent composites of western North Pacific model tropical storms use model tropical storms from the June-October typhoon season; the 13-member ensemble simulation produces a total of 5701 model tropical storms in the period 1979-1995. The ensemble members differ in their initial conditions, which are quickly amplified by the nonlinear model dynamics to the point that specific weather events in each simulation can be considered independent from specific events in the other simulations. Therefore, we treat each model tropical storm in each of the ensembles as independent in constructing our composites. Among the 13 ensemble members there is a spread in the number of model tropical storms and their locations, as is expected due to 
the different initial conditions. However, the interannual variability signal in both number of tropical storms and their location is very robust. The characteristics of our composites are also robust, being unchanged if we use fewer ensemble members.

Our composites are created by averaging simulated fields from different storms in a storm-centered coordinate. The spatial center of the storm in each day is defined by the centroid of the low-level vorticity $(850 \mathrm{hPa})$. We center the composites in time on the first day they pass the detection criteria (here called day 0 ) and extend each track backward and forward for 15 days from that point. While all storms are included on day 0 , not all storms can be tracked 15 days before and after they pass the detection criteria. Here we produce composites using only those storms' whose lifespan covers at least the period from day -7 to day +7. A total of 1832 storms satisfy this criterion. Model storms lifetimes tend to be longer than those of observed storms, as normally defined; approximately $1 / 3$ of model storms can be tracked for 15 days. The average observed lifetime of western North Pacific named tropical storms (reaching at least tropical storm strength) in the period 1979-1995 is 7.5 days, with only $7 \%$ of these storms lasting more than 15 days (JTWC, 2002). A possible explanation is that the model's eastward bias in the initial formation location results in very few model storms' making landfall. A typical model storm thus remains over the ocean over the ocean for a longer time than does a typical real storm, which allows the model storms to last longer. However, in general, a detailed comparison between model and observed storm lifetimes is problematic, because of the differences in their intensities. The storm lifetime depends on the definition of the start and end points, which in turn depend on somewhat arbitrary intensity thresholds in both the model and observations. Because model storms never match observed ones in intensity, the thresholds differ greatly and there can be no precise algorithm for equating a given intensity in a model storm with another (stronger) intensity in an observed one. We have not attempted to tune our tracking criteria to bring the model storms' lifetimes more in line with observations.

Our figures show time series only for the period from day -7 to day +7 , so that for the period shown the composites include exactly the same storms at all times. If instead we were to keep all storms in the composites, including ones whose tracks begin after day -7 or end before day +7 , artifacts would be introduced into the time series by the dropping in and out of different systems. In some cases, as we have verified by experimentation, this can make even a qualitative difference in the time series.

The spatially varying and temporally varying composite fields (Fig. 4) are computed as ensemble means at each grid point, in a storm-centered box of size $7 \times 7$ grid boxes (corresponding to a square box with sides of approximately $16.8^{\circ}$ ), over all the tracked storms at that day (relative to day 0). Time-dependent spatial means, shown in many of our figures as time series, are computed first by producing box spatial averages over the same region for each storm and then averaging the resulting time series over the ensemble. The box size chosen is adequate to enclose the primary anomalies in all fields, as can be seen in Fig. 4. In addition to composite means, extreme values (maximum and minimum), standard deviations and skewnesses of physical fields, all as functions of time relative to day 0 , are computed over the distribution of storms used in the composite. The maximum wind speed and minimum sea level pressure are computed for each storm individually as the maximum and minimum value at any grid point within the $7 \times 7$ box at the time in question, and then averaged over all storms at that time to produce the composite maximum and minimum for that time.

When computing composite quantities, it is useful to have some way of quantifying how strongly the various fields are perturbed by the presence of a tropical disturbance in the model. A method which has been useful in analyzing observations of tropical cyclogenesis has been to identify precursor storms which appear likely to intensify into tropical cyclones, and then classify those as "developing" or "non-developing" according to whether they do in fact undergo genesis (McBride, 1981a; McBride and Zehr, 1981; McBride, 1981b; Zehr, 1992). Here, even the mature storms are sufficiently weak that such a distinction is not practical. A "non-developing" storm would be difficult to distinguish objectively from background model variability which is entirely unrelated to tropical cyclones. Therefore, we simply define anomalies for each storm relative to monthly mean model climatology for the date and location of that storm, and then these anomalies are averaged over all storms to produce time series of anomalous fields.

\section{Results}

Horizontal maps of the composite $850 \mathrm{hPa}$ vorticity, surface wind-speed, precipitation and $850 \mathrm{hPa}$ relative humidity at day 0 are shown in Fig. 4. The largest vorticity values are found (by construction) in the storm center, near the largest relative humidity values, which have a small shift to the east. The precipitation maximum occurs to the east of the storm center. We might find in this a vague similarity to observations which show precipitation maxima in real tropical cyclones to be asymmetric about the storm center (Frank, 1977). The surface wind-speed has two maxima around the storm center, where a local minimum of the surface wind-speed is located. The horizontal structure of the storms at day 0 justifies our choice for the storm composite size.

For the rest of this section, we examine time series of various composite quantities averaged in space around the storm centers, as described above.

The time evolution of the composite mean (relative) vorticity and anomalous vorticity $(850 \mathrm{hPa})$ is shown in Fig. 5 . The mean and anomalous vorticity have nearly identical time dependence. The initial vorticity anomaly at day -7 is significantly positive, suggesting the presence of an initial disturbance days before the tropical storm appears, similar to the description given by Zehr (1992) for observed tropical cyclones. This anomaly stays 


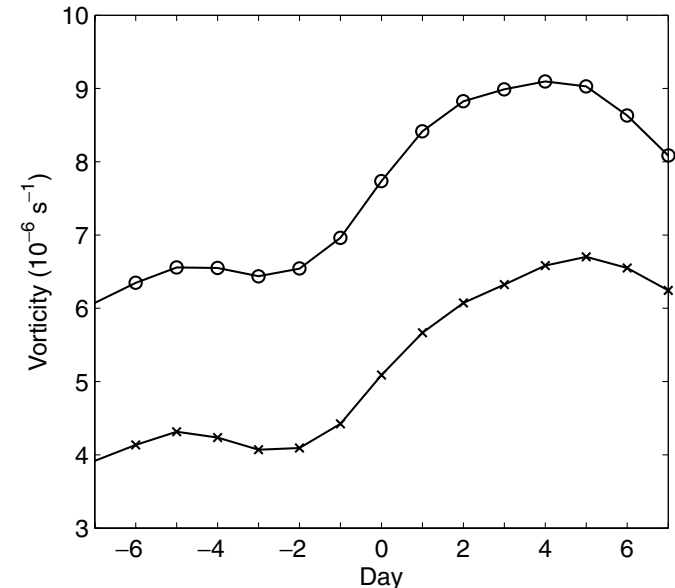

Fig 5. Time evolution of the composite mean vorticity (o) and anomalous vorticity $(\times)$ for all storms (in $\mathrm{s}^{-1}$ ).

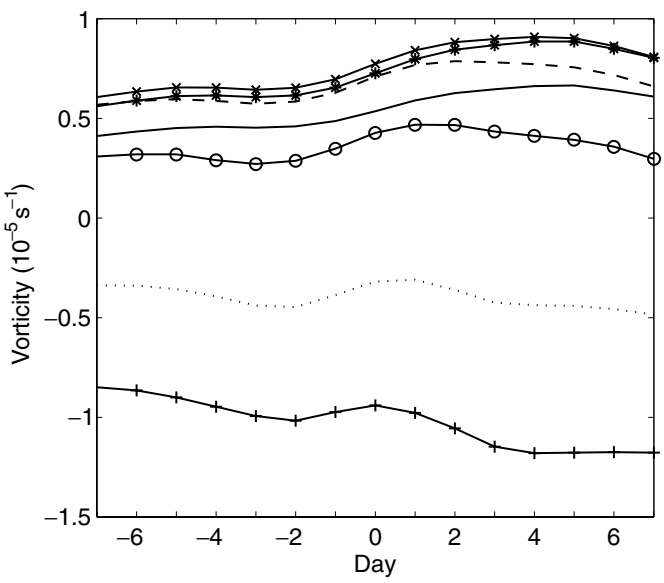

Fig 6. Time evolution of the composite mean anomalous vorticity at different pressure levels: $1000 \mathrm{hPa}$ (continuous line), $925 \mathrm{hPa}(*), 850$ $\mathrm{hPa}(\times), 700 \mathrm{hPa}$ (dashed line), $500 \mathrm{hPa}(\circ), 300 \mathrm{hPa}$ (dotted line) and $200 \mathrm{hPa}(+)\left(\right.$ in s$\left.^{-1}\right)$.

roughly constant until about day -3 , where it has a very weak minimum, after which it sharply increases for several days, with a maximum around day 5 and a decrease thereafter. Though we expect an initial vorticity anomaly due to the way the composites were built, the anomalous composite initial vorticity could have been significantly lower while still being trackable. Further, the fact that the anomalous vorticity stays roughly constant in time for several days before the intensification at day -3 , as opposed to a continuous increase in intensity for the whole period, suggests the presence of a well defined initial disturbance distinct from the cyclone which eventually forms.

The time evolution of the anomalous vorticity at other levels of the lower troposphere is broadly similar, as shown in Fig. 6, with the expected difference that the vorticity signal at upper levels has the opposite sign of that at lower levels. The anomalous vorticity at $200 \mathrm{hPa}$ has its maximum (analogous to a minimum at lower levels) around day 0 rather than day -3 , and overall has

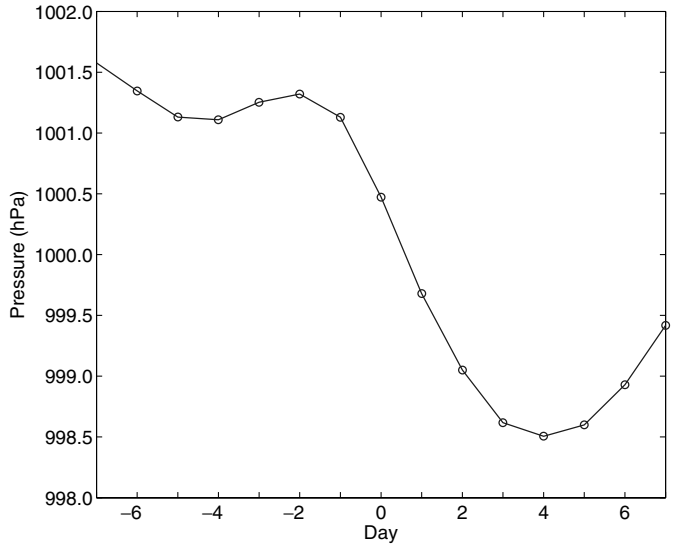

Fig 7. Time evolution of the composite minimum surface pressure (o) for all model tropical storms (in $\mathrm{hPa}$ ).

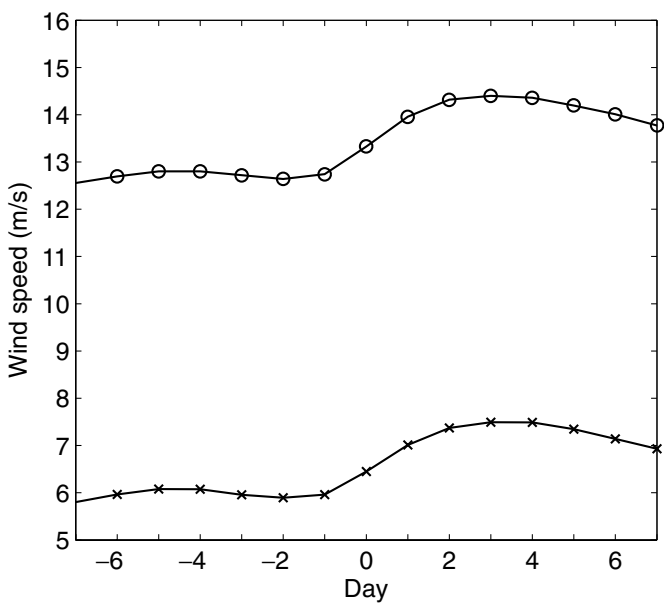

Fig 8. Time evolution of the composite maximum surface winds (o) and maximum anomalous surface winds $(x)$ for all the tropical storms (in $\mathrm{m} \mathrm{s}^{-1}$ ).

larger amplitude than the lower level signals, something which would not be true in an observed tropical cyclone, at least not locally near the storm center.

The composite minimum surface pressure (Fig. 7) has a temporal structure quite similar to that of the vorticity, with a negative anomaly at day -7 compared to climatology (which is not shown), a weak maximum (analogous to a vorticity minimum at low levels in its relation to storm intensity) at day -3 , and a sharp decrease therafter to a minimum in this case on day 4 . The composite maximum surface wind speed (Fig. 8) has broadly similar behavior, but is flatter before day 0 , has an almost undetectably weak minimum around day -2 , and then increases somewhat. The overall magnitude of the surface wind speed in the composite systems is not particularly impressive, but it should be kept in mind that different systems reach their peak wind speeds at different times, so that the compositing prevents us from seeing the very largest wind speeds which occur in each storm. The local minimum in the amplitude of many of the variables analysed 


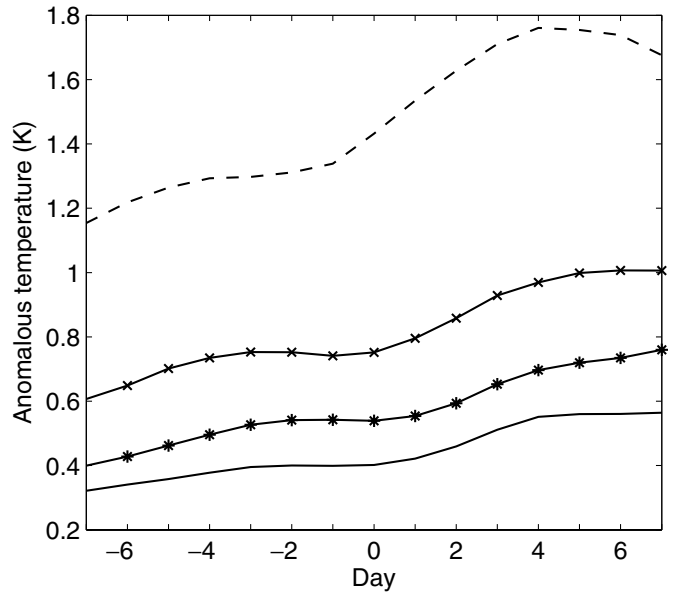

Fig 9. Time evolution of the composite mean anomalous temperature at differents pressure levels: $850 \mathrm{hPa}$ (continuous line), $700 \mathrm{hPa}(*)$, $500 \mathrm{hPa}(\times)$ and $300 \mathrm{hPa}$ (dashed line) (in K).

prior to the development is statistically robust, having also been present when composites of different durations were used, such as days -10 to 10 and -5 to 5 .

The anomalous temperature at different pressure levels is shown in Fig. 9. Somewhat similarly to the variables shown in the preceding figures, the composite anomalous temperature at different levels is significantly positive at day -7 , increases at most weakly for the first seven days or so, and then increases more sharply beginning around day 0 . This increase in the rate of change in the temperature occurs later than for the vorticity, surface pressure and surface wind, which began their more rapid increases in intensity around day -2 or -3 . The largest values of mean anomalous temperature occur at upper levels and the smallest at lower levels, consistent with a roughly moist adiabatic structure. After day 5 or so the anomalous temperature at $300 \mathrm{hPa}$ begins to diminish, while it remains constant or continues to increase weakly at lower levels.

The fact that the signals in $850 \mathrm{hPa}$ vorticity, surface pressure and surface wind, and $850 \mathrm{hPa}$ temperature all begin intensifying at approximately the same time may be viewed as different than observed tropical cyclogenesis in that in observations, a midlevel, cold-core vortex forms first and then extends downward to the surface and develops a surface warm core (e.g. Bister and Emanuel, 1997). We do not currently have a definitive explanation for this difference. It could possibly be explained by excessive vertical momentum transport by the convective scheme or vertical diffusion of momentum, but we have not attempted to diagnose this directly.

The composite mean anomalous relative humidity $(\mathrm{RH})$ for different levels is shown in Fig. 10. The anomalous RH is positive at all times and levels, with larger values at higher levels. The RH anomalies at 850 and $700 \mathrm{hPa}$ begin at 3 and $4 \%$ and increase slightly throughout the storm evolution, with weak minima around day 0 and 1 respectively. The RH at 500 and $300 \mathrm{hPa}$

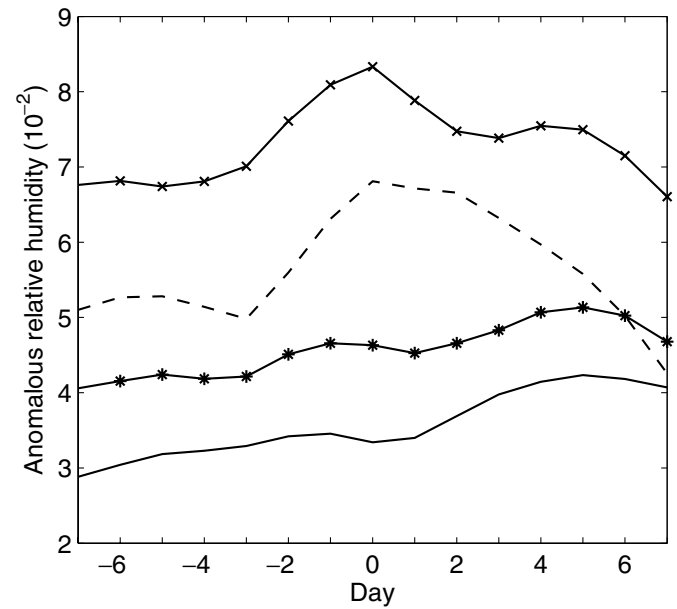

Fig 10. Time evolution of the composite mean anomalous relative humidity at $850 \mathrm{hPa}$ (continuous line), $700 \mathrm{hPa}(*), 500 \mathrm{hPa}(\times)$ and $300 \mathrm{hPa}$ (dashed line).

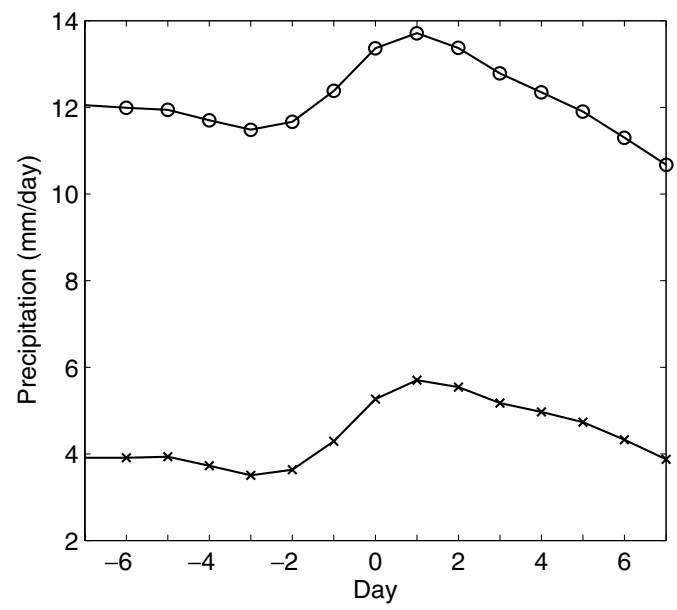

Fig 11. Time evolution of the composite mean ( $(0)$ and anomalous $(x)$ precipitation $\left(\mathrm{mm} \mathrm{d}^{-1}\right)$.

have distinct "bumps" centered roughly on day 0. Moistening at these levels is presumably caused by deep convection. This is consistent with the composite precipitation (Fig. 11), which has a similar temporal structure to that of the upper level RH. The precipitation anomaly at day -7 is $4 \mathrm{~mm} \mathrm{~d}^{-1}$, increasing to about $6 \mathrm{~mm} \mathrm{~d}^{-1}$ on days $0-1$ and decreasing back to around 4 $\mathrm{mm} \mathrm{d}^{-1}$ over the succeeding several days.

The temporal behavior of the standard deviation and skewess of different variables over the distribution of model storms was also analysed. An interesting signal is found in the skewness of the $850 \mathrm{hPa} \mathrm{RH}$. Because the mean $850 \mathrm{hPa} \mathrm{RH}$ is high (around $80 \%$ ), and the maximum possible is $100 \%$, we naively expect negative skewness, in general. The standard deviation of the $\mathrm{RH}$ at $850 \mathrm{hPa}$ (not shown) is approximately constant in time with a value of $5 \%$, about one-fourth of the separation between the mean RH and the maximum of $100 \%$. At most levels and times, 


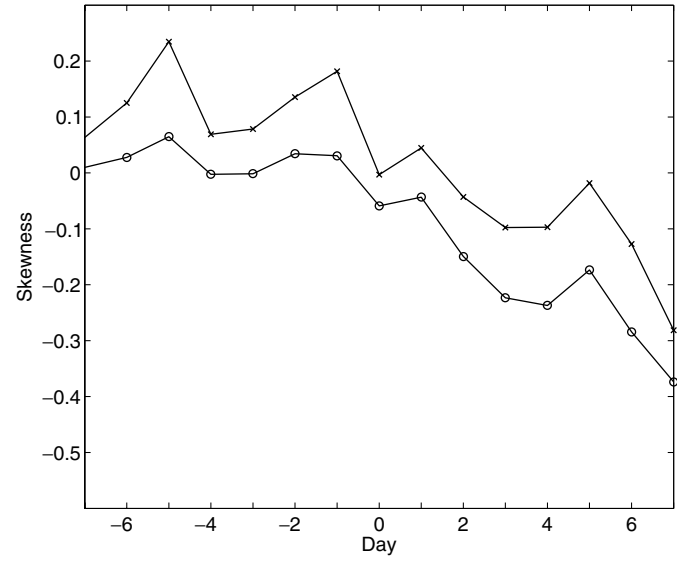

Fig 12. Time evolution of the skewness of the composite mean relative humidity ( $\circ$ ), and of the anomalous relative humidity $(\times)$ at $850 \mathrm{hPa}$.

a negative skewness is indeed found. However, at $850 \mathrm{hPa}$ the RH skewness is slightly positive for several days just before and through day 0 , as shown in Fig. 12. This positive skewness, occurring prior to day 0 , suggests the existence of a constraint excluding low RH values from the distribution. This is consistent with the idea, and previously observed and simulated fact, that a necessary condition for cyclogenesis is high RH values in the lower and middle troposphere (Gray, 1979; Rotunno and Emanuel, 1987; Emanuel, 1989; 1995). The skewness signal suggests that the model may obey a similar constraint, such that precursor disturbances with lower $850 \mathrm{hPa} \mathrm{RH}$ do not develop further and thus are excluded from the composite.

The composite RH skewness decreases throughout the period, becoming negative around day 0 and decreasing more rapidly thereafter. The skewness of the anomalous RH remains less negative than that of the composite mean, but nonetheless it seems that the systems at later stages of development can sustain drier lower tropospheres than those at earlier stages of development.

The model climatological wind shear for the period JuneNovember is shown in Fig. 14. The time series of the composite mean shear, mean anomalous shear and mean climatological shear are shown in Fig. 13. The shear is defined as the difference of the zonal velocity averaged over the compositing region at 200 and $850 \mathrm{hPa}$. The spatial averaging is done first and then the shear computed, so it is an environmental, rather than directly disturbance-related shear (which is not to say that the presence of the disturbance does not influence it in any way). The composite mean shear has a value near $-6 \mathrm{~m} \mathrm{~s}^{-1}$ at day -7 , a weak minimum at day -2 (which is a maximum in absolute value), and increases (decreases in absolute value) thereafter. The anomalous shear varies between -3 and $-1 \mathrm{~m} \mathrm{~s}^{-1}$ throughout the period.

The decrease in magnitude of the shear after day -2 might be viewed as consistent with a causally controlling role for the shear, as has been hypothesized for real tropical cyclogenesis (Gray, 1979; McBride, 1981a; McBride and Zehr, 1981; McBride, 1981b). We can imagine that as the initial disturbance begins to organize, it drifts poleward into a region of weaker shear (see Fig. 13). The similarity between the time series of composite mean and climatological shear suggests that the decrease in shear is primarily due to the mean storm trajectory from regions of higher to lower shear (easterly shear becoming less so) rather than dynamical changes in shear at a given location. We can hypothesize that if the shear reduces below a certain threshold value(3-4 $\mathrm{m} \mathrm{s}^{-1}$ is suggested by the figure) intensification occurs, while otherwise it does not, thus excluding storms which do not propagate into weak-shear regions from the composites. At the same time, the tendency of the storms to move northward will produce the same time evolution of the shear even if the intensification occurs for entirely independent reasons, so from the evidence here we cannot make a conclusive judgment about the role of shear in the model cyclogenesis. The fact that the anomalous shear at the time of intensification has the same sign as the climatological shear also tends to weaken the argument for the causal control by shear, in that it implies that storms form in an environment of (slightly) anomalously large shear.

The terms in the composite anomalous net column-integrated moist static energy budget [surface sensible and latent heat fluxes at the surface, and radiative shortwave and longwave fluxes at the top of the atmosphere (TOA)] are shown in Fig. 15. TOA

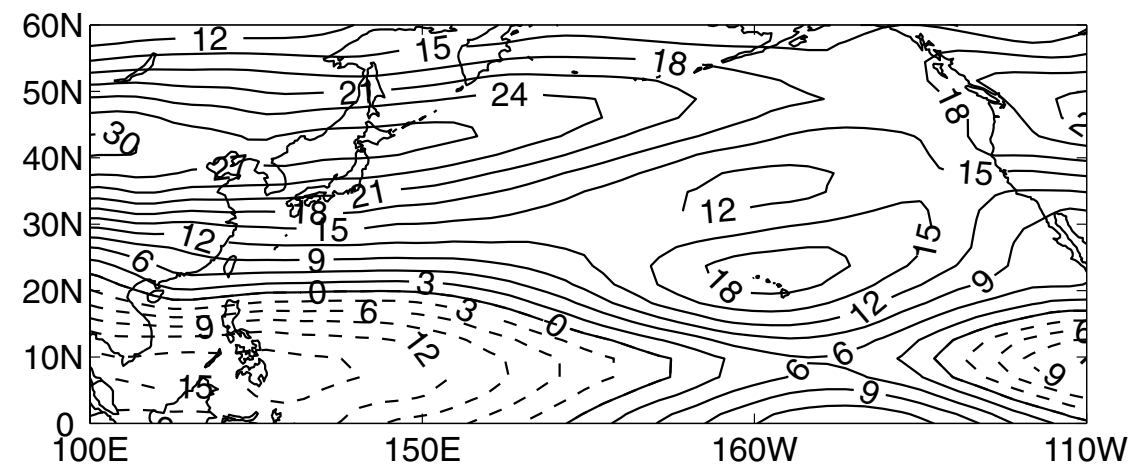

Fig 13. ECHAM4.5 June-November climatological wind shear in the western North Pacific. 


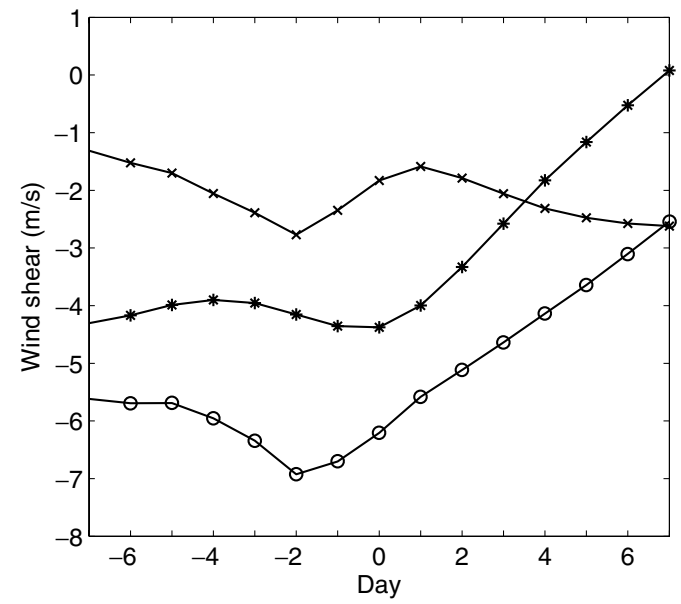

Fig 14. Time evolution of the composite mean (o), anomalous $(\times)$ and climatological shear $(*)$ (in $\left.\mathrm{m} \mathrm{s}^{-1}\right)$.

(a) and surface (b) fluxes are shown in separate panels; both are defined as positive downward. Also shown (redundantly) in each panel is the net vertical anomalous moist static energy flux convergence due to the sum of these terms. This last quantity has a weak minimum on day -3 and then a sharp increase with a maximum on day 2 , and is positive through- out. The tendency of column-integrated moist static energy is quite small, so that this vertical flux convergence implies a compensating horizontal export of moist static energy, as occurs in real tropical cyclones (McBride, 1981b) as well as the convective regions of larger-scale, thermally direct climatological circulations (Neelin and Held, 1987). Of the model energy fluxes entering to the anomalous moist static energy flux convergence, the dominant ones are the anomalous surface latent heat flux and the anomalous outgoing longwave radiation (OLR) flux at the TOA. Each contributes very similarly to the other in both magnitude and temporal structure. The shortwave flux also has anomalies comparable in magnitude to those two terms $\left(\sim 20-30 \mathrm{~W} \mathrm{~m}^{-2}\right)$ at both surface and TOA, although this is largely nondivergent in the atmosphere, so that the anomaly in atmospheric solar absorption is closer to $10 \mathrm{~m} \mathrm{~s}^{-2}$ and also has less temporal variation than the surface latent heat flux and OLR.

The importance of the surface latent heat flux in the cyclogenesis process is described in theoretical (Rotunno and Emanuel, 1987) and observational (Gray, 1979) studies. The OLR signal reflects the model's production of high clouds at the location of model tropical storms, reducing the radiative cooling of the atmosphere. This provides a positive feedback to the moist static energy budget of comparable magnitude to the surface latent heat

(a)

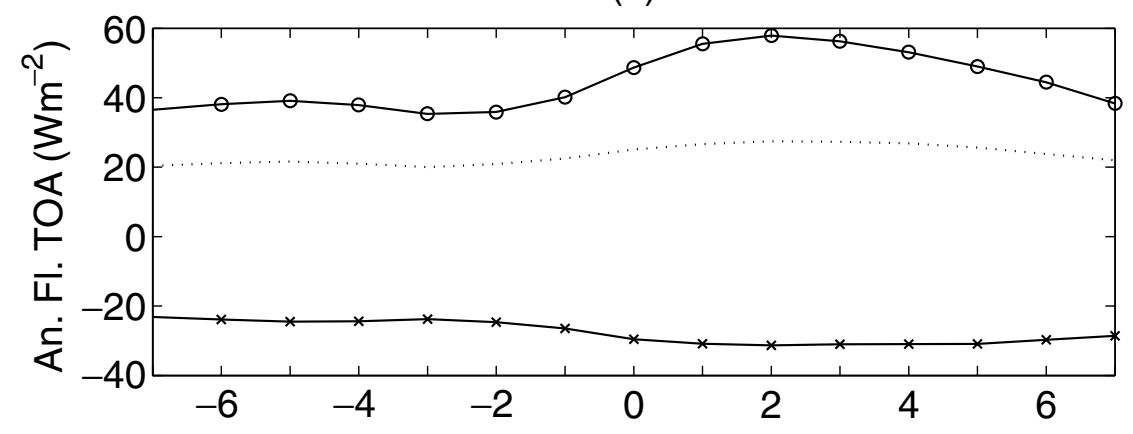

(b)

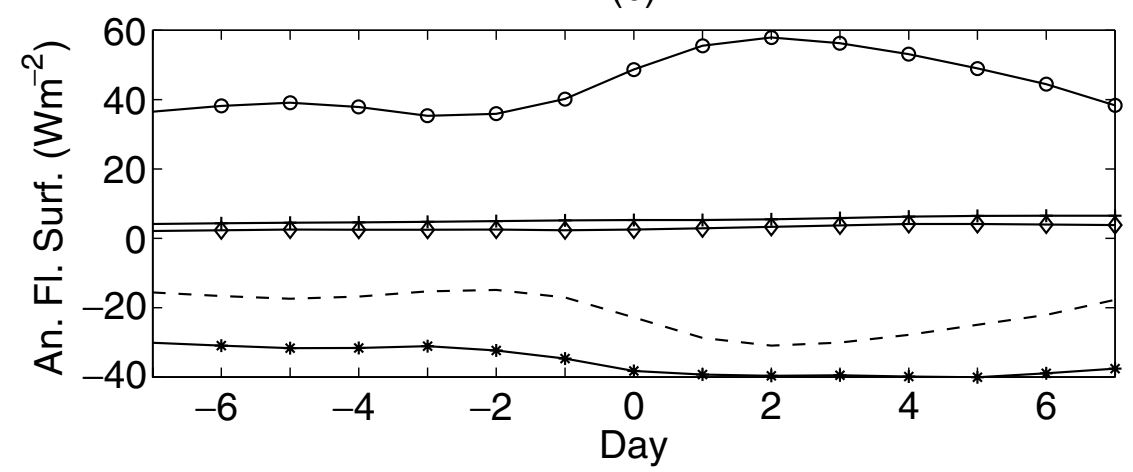

Fig 15. Time evolution of the composite mean anomalous radiation and heat fluxes magnitudes at the top of the atmosphere (TOA) (a): outgoing longwave radiation flux (dotted line), short wave flux at TOA $(\times)$; and surface $(b)$ : longwave $(+)$ and shortwave $(*)$ fluxes at the ground, latent (dashed line) and sensible $(\diamond)$ heat fluxes (in $\mathrm{W} \mathrm{m}^{-2}$ ). The moist static energy forcing $(\circ)$ is shown in both panels. 
(a)
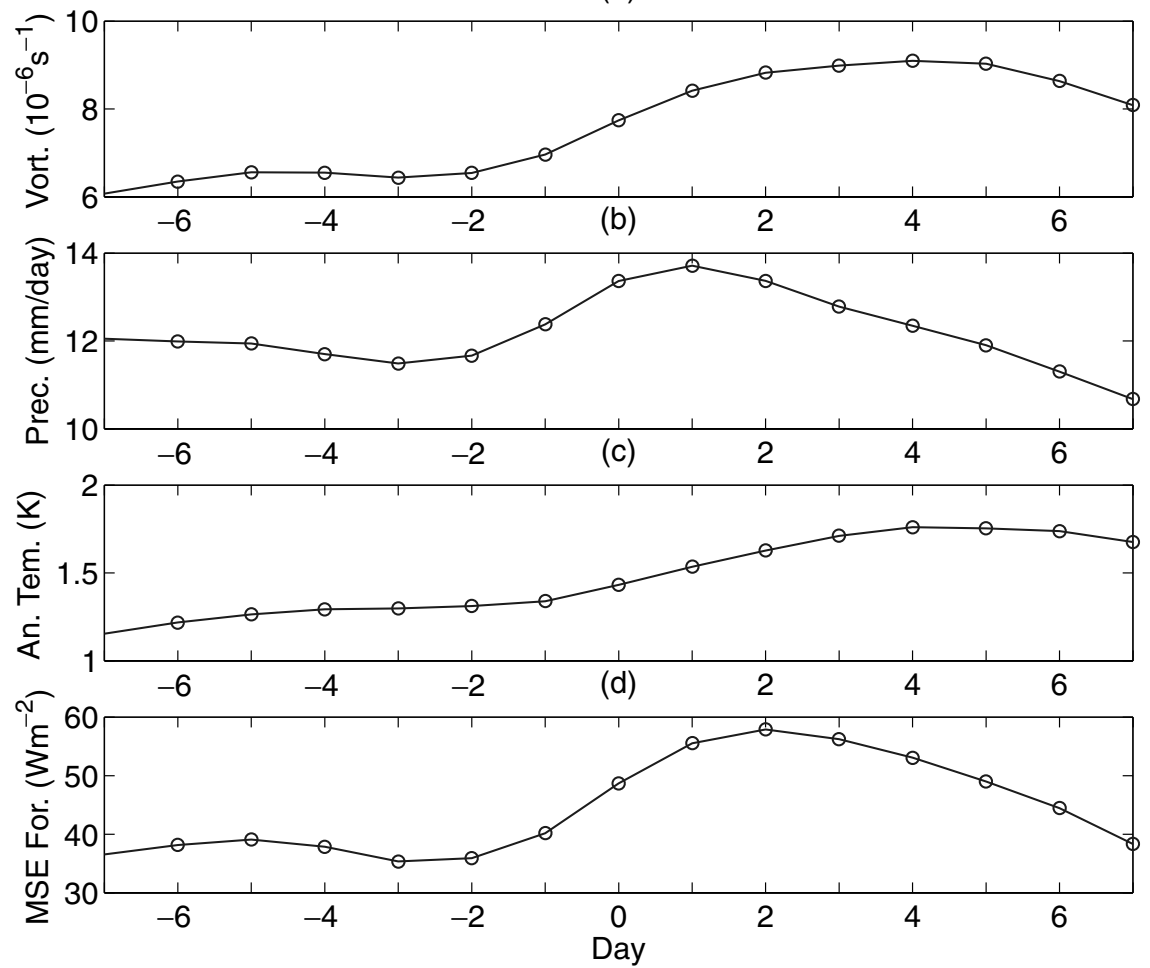

Fig 16. Time evolution of the composite mean (a) $850 \mathrm{hPa}$ vorticity $\left(\mathrm{s}^{-1}\right)$, (b) precipitation $\left(\mathrm{mm} \mathrm{d}^{-1}\right)$, (c) $300 \mathrm{hPa}$ anomalous temperature (K) and (d) moist static energy forcing $\left(\mathrm{W} \mathrm{m}^{-2}\right)$.

flux in the model. Although reduced radiative cooling surely occurs in real tropical cyclones, it is probably not as large an effect as surface fluxes, which are surely underestimated in our model storms due to the excessively weak surface winds in the simulated storms.

\section{Synthesis}

Figure 16 repeats the time series for composite mean $850 \mathrm{hPa}$ vorticity and precipitation, and anomalous $300 \mathrm{hPa}$ temperature and column-integrated net moist static energy forcing, from the earlier figures, aligned so that the temporal relationships between fields can be more clearly discerned. At day -7 , there are significant anomalies in all fields. As with real tropical cyclones, the model disturbances evolve from pre-existing ones of finite amplitude. As shown in earlier figures, the initial disturbances also have positive RH anomalies throughout the troposphere.

Many of the fields, including all shown in Fig. 16 but the anomalous temperature, have a weak local minimum around day -3 . Because of its small amplitude we might be tempted to disregard this feature, but because it occurs in so many fields it seems to be significant. We have no explanation for it at present, nor are we aware of a similar feature having been observed in real tropical cyclogenesis.

Over a period of several days centered on day 1 , there is a burst of enhanced precipitation, which further moistens the upper and middle troposphere (Fig. 10). The moist static energy forcing, which includes equal components from radiative and surface flux feedbacks, peaks a day later on day 2 . The radiative feedback presumably comes from high cloudiness associated with the enhanced precipitation. The surface flux feedback presumably derives from the vortex stretching caused by the large-scale upward motion and horizontal divergence associated with the enhanced precipitation. This vortex stretching spins up the freetropospheric vorticity, which increases to a broad plateau centered around day 5, along with the temperature (the two being associated by gradient wind balance). Perhaps unrealistically, this spinup is communicated quickly to the surface (Fig. 6), whether by vertical diffusion of momentum, parameterized convective momentum transport, or another mechanism. The resulting increase in surface winds drives the surface flux increase. The surface flux enhancement decays somewhat faster than the radiative perturbation, perhaps because of near-surface moistening which reduces the air-sea humidity contrast. This causes a decay in the net moist static energy forcing which begins earlier than that in the dynamical fields.

Starting on day -2 , the same time as the dynamical fields begin their increases, the environmental shear begins to decrease in magnitude. This could be because only storms which manage to move to regions of weaker shear intensify. It could also be because those storms which do develop, for other reasons, happen 
to move to regions of weaker climatological shear. If the decrease in shear occurred earlier, or if the composite mean shear on day -7 were smaller in magnitude than the climatological value, it would be easier to assign a major causal role to the shear than, in our view, it is.

\section{Conclusions}

We have studied time-dependent composites of tropical storms over the western north Pacific in a low-resolution GCM.

All the variables which are related to storm strength begin at day -7 with anomalies of significant strength. In many of the composite time series, a sharp increase (decrease, in the case of surface pressure) in the mean value of the variable occurs after a weak minimum centered around day -3 . At that point a burst of enhanced convection occurs. This spins up the vorticity and drives an enhancement in the net moist static energy forcing, about half of which is radiative and half of which is due to enhanced surface latent heat flux. The moist static energy forcing peaks a day later than the precipitation, and both begin to decay earlier than the dynamical fields which have broad plateaus centered around day 4 or 5 .

Taken altogether, the composite mean disturbance appears to begin as a synoptic-scale, convectively coupled vortex. Its degree of coupling to convection at some point increases, leading to intensification. The overall timescale of development and decay is on the order of a week. Some features of the model "tropical cyclogenesis" seem qualitatively similar to observations, making allowances for the low amplitude and large spatial scale of the model disturbances. Other features, such as the simultaneous spinup at the surface and aloft, and the local amplitude minimum prior to development, are to our knowledge unrealistic even qualitatively.

On balance, we view the composite time series as supporting the idea that the disturbances can meaningfully be viewed as the analogous disturbances to tropical cyclones which occur in the model. This is not the same as saying the disturbances "are" tropical cyclones. Rather, we mean that the good agreement between the model's seasonal cycle in storm number and that in observations is not an accident, or purely a result of tuning of the storm detection parameters. Instead, it occurs because the model feels some large-scale constraint on the number of tropical cyclones in the basin, presumably similar to that felt by the real atmosphere. It is able to respond by producing disturbances that have enough similarities to real tropical cyclones on the large scale to satisfy those constraints in a way that can be quantified by algorithms whose criteria are based, however loosely, on empirical knowledge of real tropical cyclones. Previous studies have come to similar conclusions, that there is something realistic about the tropical storms in low-resolution models, despite the obvious unrealistic features caused by low resolution, by looking at the disturbances' instantaneous structure. Here, we provide another line of evidence by looking at the time-dependent evo- lution or "genesis". These different sorts of evidence, together with the good simulation of the annual cycle in storm number, slightly enhance, or at least do not reduce our confidence in the idea of using low-resolution models for seasonal tropical cyclone forecasting. The real test, of course, can only come from actually producing such forecasts and verifying them against observations.

If nothing else, our results provide a starting point for understanding in a more mechanistic way how the model disturbances form, and a basis for comparison with other models, the same model at higher resolution, or, ideally, with observations.

\section{Acknowledgments}

We thank the Max-Planck Institute for Meteorology (Hamburg, Germany) for making their model ECHAM accessible to IRI. We thank Drs. Michael K. Tippett (IRI), Stephen E. Zebiak (IRI), Kerry Emanuel (MIT) and Lennart Bengtsson (MPI) for their comments on an earlier version of this paper. We also thank Dr. M. Benno Blumenthal for the IRI data library.

\section{References}

Bengtsson, L. 2001. Hurricane threats. Science 293, 440-441.

Bengtsson, L., Böttger, H. and Kanamitsu, M. 1982. Simulation of hurricane-type vortices in a general circulation model. Tellus 34, 440 457.

Bengtsson, L., Botzet, M. and Esh, M. 1995. Hurricane-type vortices in a general circulation model. Tellus 47A, 175-196.

Bister, M. and Emanuel, K. A. 1997. The genesis of hurricane Guillermo: TEXMEX analyses and a modeling study. Mon. Wea. Rev. 125, 26622682.

Broccoli, A. J. and Manabe, S. 1990. Can existing climate models be used to study anthropogenic changes in tropical cyclone climate? Geophys. Rev. Lett. 17, 1917-1920.

Camargo, S. J. and Zebiak, S. E. 2002a. Improving the detection and tracking of tropical storms in Atmospheric General Circulation Models. Wea. Forecasting 17, 1152- 1162

Camargo, S. J. and Zebiak, S. E. 2002b. Variability of tropical storms in Atmospheric General Circulation Models. Proc. 25th Conf. on Hurricanes and Tropical Metereology, American Metereological Society, San Diego, CA, 148-149.

Chan, J. C. L. and Kwok, R. H. F. 1999. Tropical cyclone genesis in a global numerical weather prediction model. Mon. Wea. Rev. 127, 611-624.

Chan, J. C. L., Shi, J. E. and Lam, C. M. 1998. Seasonal forecasting of tropical cyclone activity over the western North Pacific and the South China Sea. Wea. Forecasting 13, 997-1004.

Chen, T., Weng, S. P., Yamazaki, N. and Kiehne, S. 1998. variation in the tropical cyclone activity over the western North Pacific. Mon. Wea. Rev. 126, 1080-1090.

Chia, H. H. and Ropelewski, C. F. 2002. The interannual variability in the genesis location of tropical cyclones in the Northwest Pacific. $J$. Climate 15, 2934-2944.

Emanuel, K. A. 1989. The finite-amplitude nature of tropical cyclogenesis. J. Atmos. Sci. 46, 3431-3456. 
Emanuel, K. A. 1995. Sensitivity of tropical cyclones to surface exchange coefficients and a revised steady-state model incorporating eye dynamics. J. Atmos. Sci. 52, 3969-3976.

Frank, W. M. 1977. The structure and energetics of tropical cyclone I Storm structure. Mon. Wea. Rev. 105, 1119-1135.

Goddard, L., Mason, S. J., Zebiak, S. E., Ropelewski, C. F., Basher, R. E. and Cane, M. A. 2001. Current approaches to seasonal to interannual climate predictions. Int. J. Climatol. 21, 1111-1152.

Gray, W. M. 1979. Metereology over the tropical oceans. In: Hurricanes: Their formation, structure and likely role in the tropical circulation (ed. D. B. Shaw). R. Meteorol. Soc., London, 155-218.

Gray, W. M., Landsea, C. W., Mielke, Jr., P. W. and Berry, K. J. 1993. Predicting Atlantic basin seasonal tropical cyclone activity by 1 August. Wea. Forecasting 8, 73-86.

Haarsma, R. J., Mitchell, J. F. B. and Senior, C. A. 1993. Tropical disturbances in a GCM. Clim. Dynam. 8, 247-257.

JTWC, 2002. Joint Typhoon Warning Center Tropical Cyclone Best Track Data Site. Available on line at http://www.npmoc.navy.mil.

Krishnamurti, T. N. 1988. Some recent results on numerical weather prediction over the tropics. Aust. Meteorol. Mag. 36, 141-170.

Krishnamurti, T. N. and Oosterhof, D. 1989. Prediction of the life cycle of a supertyphoon with a high-resolution global model. Bull. Am. Meteorol. Soc. 70, 1218-1230.

Krishnamurti, T. N., Oosterhof, D. and Dignon, N. 1989. Hurricane prediction with a high resolution global model. Mon. Wea. Rev. 117, 631-669.

Lander, M. A. 1994. An exploratory analysis of the relationship between tropical storm formation in the western North Pacific and ENSO. Mon. Wea. Rev. 122, 636-651.

Landman, W. A., Seth, A. and Camargo, S. J. 2002. The effect of regional climate model domain choice on the simulation of tropical cyclone-like vortices in the southwestern indian ocean. IRI Technical Report 02-06, International Research Institute for Climate Prediction, Palisades, NY, $31 \mathrm{pp}$.

Manabe, S., Holloway, J. L. and Stone, H. M. 1970. Tropical circulation in a time-integration of a global model of the atmosphere. J. Atmos. Sci. 27, 580-613.

Mason, S. J., Goddard, L., Graham, N. E., Yulaeva, E., Sun, L. Q. and Arkin, P. A. 1999. The IRI seasonal climate prediction system and the $1997 / 98$ El Niño event. Bull. Am. Meteorol. Soc. 80, 18531873

McBride, J. L. 1981a. Observational analysis of tropical cyclone formation. Part I: Basic description of data sets. J. Atmos. Sci. 38, 1117-1131.

McBride, J. L. 1981b. Observational analysis of tropical cyclone formation. Part III: Budget analysis. J. Atmos. Sci. 38, 11521166.

McBride, J. L. and Zehr, R. 1981. Observational analysis of tropical cyclone formation. Part II: Comparison of non-developing versus nondeveloping Systems. J. Atmos. Sci. 38, 1132-1151.
Neelin, J. D. and Held, I. M. 1987. Modeling tropical convergence based on the moist static energy budget. Mon. Wea. Rev. 115, 3-12.

Nicholls, N. 1992. Recent performance of a method for forecasting Australian seasonal tropical cyclone activity. Aust. Meteorol. Mag. 40, $105-110$.

Roeckner, E., Arpe, K., Bengtsson, L., Christoph, M., Claussen, M., Dümenil, L. Esch, M., Giorgetta, M., Schlese, U. and Schulzweida, U. 1996. The atmospheric general circulation model ECHAM-4: Model description and simulation of present-day climate. Technical Report 218, Max-Planck Institute for Meteorology, Hamburg, Germany, $90 \mathrm{pp}$

Rotunno, R. and Emanuel, K. A. 1987. An air-sea interaction theory for tropical cyclones. Part II: Evolutionary study using a non-hydrostatic axisymmetric model. J. Atmos. Sci. 44, 542-561.

Ryan, B. F., Watterson, I. G. and Evans, J. L. 1992. Tropical cyclone frequencies inferred from Gray's yearly genesis parameter: Validation of GCM tropical climate. Geophys. Res. Lett. 19, 1831-1834.

Thorncroft, C. and Pytharoulis, I. 2001. A dynamical approach to seasonal prediction of Atlantic tropical cyclone activity. Wea. Forecasting 16, 725-734.

Tsutsui, J. I. and Kasahara, A. 1996. Simulated tropical cyclones using the National Center for Atmospheric Research community climate model. J. Geophys. Res. 101, 15 013-15032.

Vitart, F. 1998. Tropical storm interannual and interdecadal variability in an ensemble of GCM integrations. Ph.D. Thesis, Princeton University, $387 \mathrm{pp}$.

Vitart, F. and Anderson, J. L. 2001. Sensitivity of Atlantic tropical storm frequency to ENSO and interdecadal variability of SSTs in an ensemble of AGCM integrations. J. Climate 14, 533-545.

Vitart, F., Anderson, J. L. and Stern, W. F. 1997. Simulation of interannual variability of tropical storm frequency in an ensemble of GCM integrations. J. Climate 10, 745-760.

Vitart, F., Anderson, J. L. and Stern, W. F. 1999. Impact of large-scale circulation on tropical storm frequency, intensity and location, simulated by an ensemble of GCM Integrations. J. Climate 12, 3237-3254

Vitart, F. D. and Stockdale, T. N. 2001. Seasonal forecasting of tropical storms using coupled GCM integrations. Mon. Wea. Rev. 129, 25212537.

Wang, B. and Chang, J. C. L. 2002. How strong ENSO events affect tropical storm activity over the Western North Pacific. J. Climate $\mathbf{1 5}$, $1643-1658$

Watterson, I. G., Evans, J. L. and Ryan, B. F. 1995. Seasonal and interannual variability of tropical cyclogenesis: Diagnostics from large-scale fields. J. Climate 8, 3052-3066.

Wu, G. and Lau, N. C. 1992. A GCM Simulation of the relationship between tropical storm formation and ENSO. Mon. Wea. Rev. 120, 958-977.

Zehr, R. M. 1992. Tropical cyclogenesis in the Western North Pacific. NOAA Technical Report NESDIS 61, NOAA, Washington, D.C., $181 \mathrm{pp}$. 